\title{
Bio-assisted synthesis of bimetallic nanoparticles featuring antibacterial and photothermal properties for the removal of biofilms
}

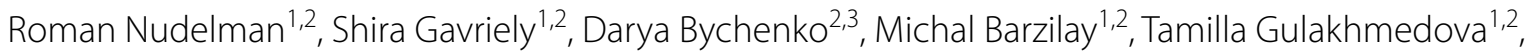
Ehud Gazit ${ }^{2,3}$ and Shachar Richter ${ }^{1,2^{*}}$ (1)

\begin{abstract}
Biofilms are responsible for about considerable amounts of cases of bacterial infections in humans. They are considered a major threat to transplant and chronic wounds patients due to their highly resistant nature against antibacterial materials and due to the limited types of techniques that can be applied to remove them. Here we demonstrate a successful in-situ bio-assisted synthesis of dual functionality nanoparticles composed of Silver and Gold. This is done using a jellyfish-based scaffold, an antibacterial material as the templating host in the synthesis. We further explore the scaffold's antibacterial and photothermal properties against various gram-negative and positive model bacteria with and without photo-induced heating at the Near-IR regime. We show that when the scaffold is loaded with these bimetallic nanoparticles, it exhibits dual functionality: Its photothermal capabilities help to disrupt and remove bacterial colonies and mature biofilms, and its antibacterial properties prevent the regrowth of new biofilms.
\end{abstract}

Keywords: Antibacterial nanoparticles, Photothermal nanoparticles, Biofilms removal, Nanofibers, Jellyfish, Bioassisted synthesis

*Correspondence: srichter@tauex.tau.ac.il

${ }^{1}$ Department of Materials Science and Engineering, Faculty

of Engineering, Tel Aviv University, 69978 Tel-Aviv, Israel

Full list of author information is available at the end of the article

(c) The Author(s) 2021. Open Access This article is licensed under a Creative Commons Attribution 4.0 International License, which permits use, sharing, adaptation, distribution and reproduction in any medium or format, as long as you give appropriate credit to the original author(s) and the source, provide a link to the Creative Commons licence, and indicate if changes were made. The images or other third party material in this article are included in the article's Creative Commons licence, unless indicated otherwise in a credit line to the material. If material is not included in the article's Creative Commons licence and your intended use is not permitted by statutory regulation or exceeds the permitted use, you will need to obtain permission directly from the copyright holder. To view a copy of this licence, visit http://creativecommons.org/licenses/by/4.0/. The Creative Commons Public Domain Dedication waiver (http://creativeco mmons.org/publicdomain/zero/1.0/) applies to the data made available in this article, unless otherwise stated in a credit line to the data. 


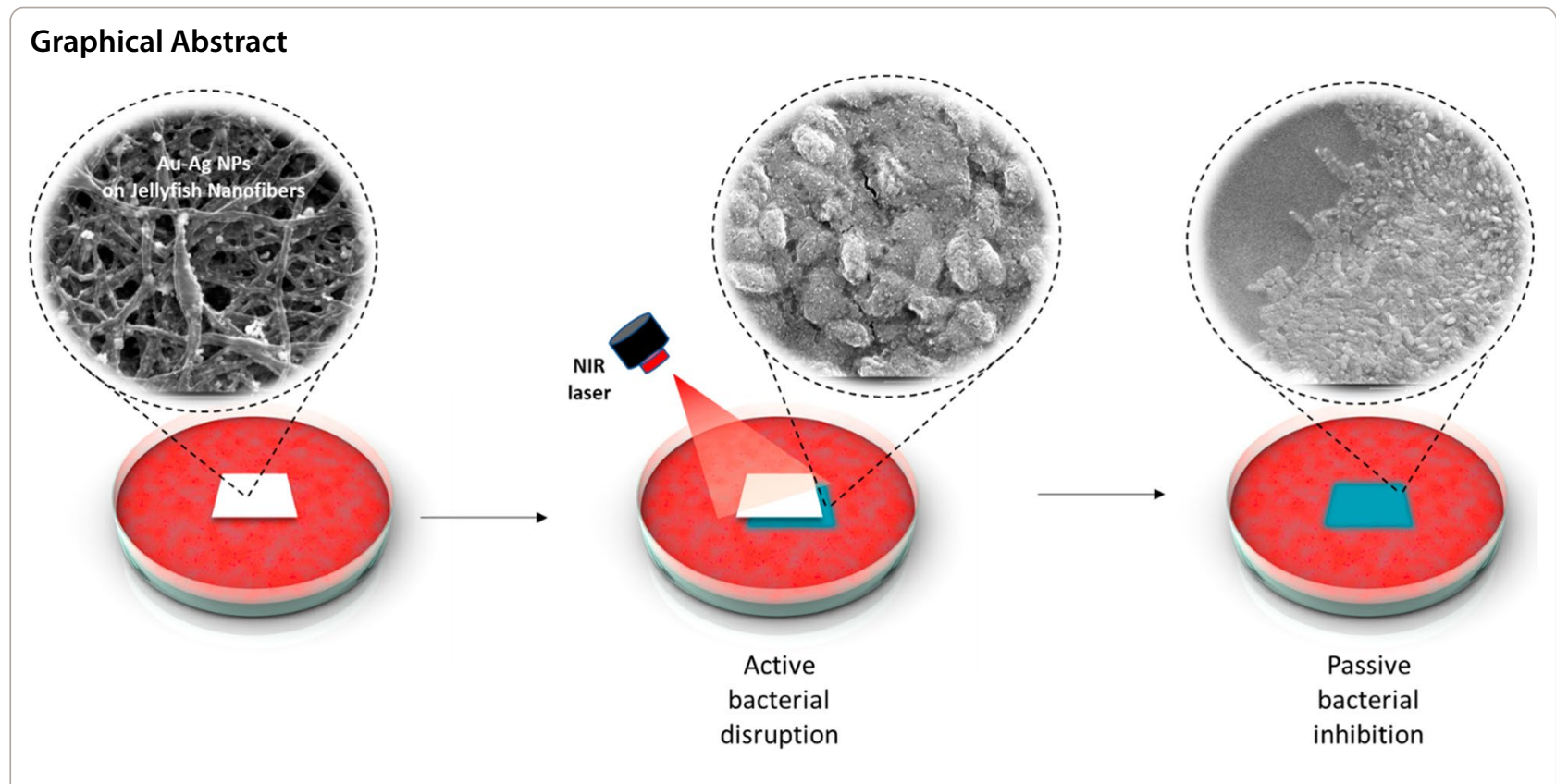

\section{Introduction}

Biofilms (BFs) are composed of microorganisms such as bacteria that tend to irreversibly attach to wet surfaces to form a hydrated matrix of extracellular polymeric substance (EPS) [1,2]. These colonies can naturally grow on various wet surfaces, including rocks, organic and inorganic materials, metal pipelines, heat exchangers, teeth, and various biomedical devices, thus presenting a significant adverse risk in a wide range of fields [3-5]. In this context, it was reported by the National Institute of Health that BFs are found in $80 \%$ of all known infections, thus causing considerable adverse economic and healthcare-related effects $[6,7]$.

Several strategies have been applied to prevent BFs formation and remove mature ones. These include the preemptive disinfection of surfaces [8] or chemical and physical disruption of already formed BFs structures followed by their mechanical removal $[6,9,10]$.

Nevertheless, none of those schemes have shown high efficiency, as fully matured BFs exhibit high resistance capabilities, which reduce the effectiveness of the abovementioned methods $[8,11]$. Moreover, most BFs-removal methodologies cannot be applied to infected sensitive surfaces such as medical devices, implants, and woundhealing, limiting their use in biomedical use. Therefore, alternative methodologies are needed to be applied that fit these applications $[12,13]$.

One of the most useful antibacterial materials that might be harnessed for this task is Silver (Ag) in the form of nanoparticles (AgNPs) since these can disintegrate the bacterial membrane and its DNA. [14, 15]
However, in fully matured BFs, AgNPs are less effective because these prevent the penetration of $\mathrm{Ag}$ ions into the BFs's inner layers $[16,17]$.

It has been suggested that the application of heat in parallel with the application of the antimicrobial NPs might help to address this problem: the local heat applied induces sufficient thermal damage to the BF's EPS allowing penetration of AgNPs that successfully damage the bacteria $[18,19]$. A suitable biocompatible material that can exhibit photo-induced localized heat while also exhibiting a mild antibacterial effect is Gold $(\mathrm{Au})$ in its various nanoparticle forms (AuNPs). For this reason, AuNPs have been extensively explored for their potential application in photothermal (PT) -based applications such as hyperthermal cancer therapy, wound healing, and biofilm control [20-22].

Thus, it can be hypothesized that using an appropriate scaffold in which AuNPs and AgNPs are embedded within, or preferably synthesized NPs composed of the two metals, is of great interest and might be used for efficient BFs removal [23-26]. In this respect, we recently reported on a non-woven biocompatible scaffold processed by the electrospinning (ES) method, allowing the in-situ one-pot spontaneous synthesis of NPs within [27]. The scaffold comprises Jellyfish nanofibers (JFNF) composed of JF's collagen, Q-mucin protein, and polycaprolactone (PCL). In this respect, we have shown that in addition to its natural wound healing characteristics, JFNF can actively and spontaneously reduce $\mathrm{Ag}$ ions and form AgNPs directly on the nanofibers' surface [27-29]. 
Here we take a step forward and report the successful in-situ synthesis of PT AuNPs, and bimetallic NPs composed of $\mathrm{Au}$ and $\mathrm{Ag}$, using the JFNF as the templating host in the synthesis. We further explore the scaffold's antibacterial and PT properties against various gramnegative and positive model bacteria with and without photo-induced heating at the Near-IR (NIR) regime $(\lambda=808 \mathrm{~nm})$. Furthermore, we show that when the scaffold is loaded with these bimetallic NPs and placed on top of mature BF, it exhibits dual functionality: Its photothermal capabilities help to disrupt and remove bacterial colonies and mature biofilms, and its antibacterial properties prevent the regrowth of new BFs.

\section{Results and discussion}

\section{JFNF: preparation and characterization}

Preparation of the JFNF was done using previously published protocol [27]. In short, locally collected jellyfish specimens (Rhopilema nomadica) were processed by mechanical cutting while the needed proteins collagen and Q-mucin were extracted by solvent precipitation and centrifugation. Next, JF proteins were dissolved and added to a PCL solution to prepare the ES solution used in a home-built electrospinning setup (Fig. 1A). Scaffold structure optimization was performed by varying the process parameters such as JF/PCL ratio, the voltage applied (13-17 kV), and tip-sample distance. Figure 1B shows the scaffold's environmental scanning electron microscopy (ESEM), highlighting its fibrous nature. For additional analysis of the scaffold (See also Additional file 1: Figures S1 and S2).

\section{In situ synthesis of AuNP and Bimetallic NPs}

As previously shown, this scaffold can be used to reduce $\mathrm{Ag}$ ions into AgNPs [27]. We attribute this phenomenon to the chemical reduction properties of Q-mucin glycoproteins' presence on the fiber surface [30,31]. Notably, as Silver's electronegativity value is $+1.93 \mathrm{eV}$, it can be concluded that it is possible to synthesize other noble metal NPs that exhibit higher electronegativity values, including $\mathrm{Au}(+2.54 \mathrm{eV})$ [32] and bimetallic NPs.

Control over the synthesis products can be achieved via the $\mathrm{pH}$ of the reaction [33] because the latter affects the proteins' ternary structure, which, in turn, determines the number of sites available for the reaction. To test this effect in our case, we synthesized AuNPs and bimetallic

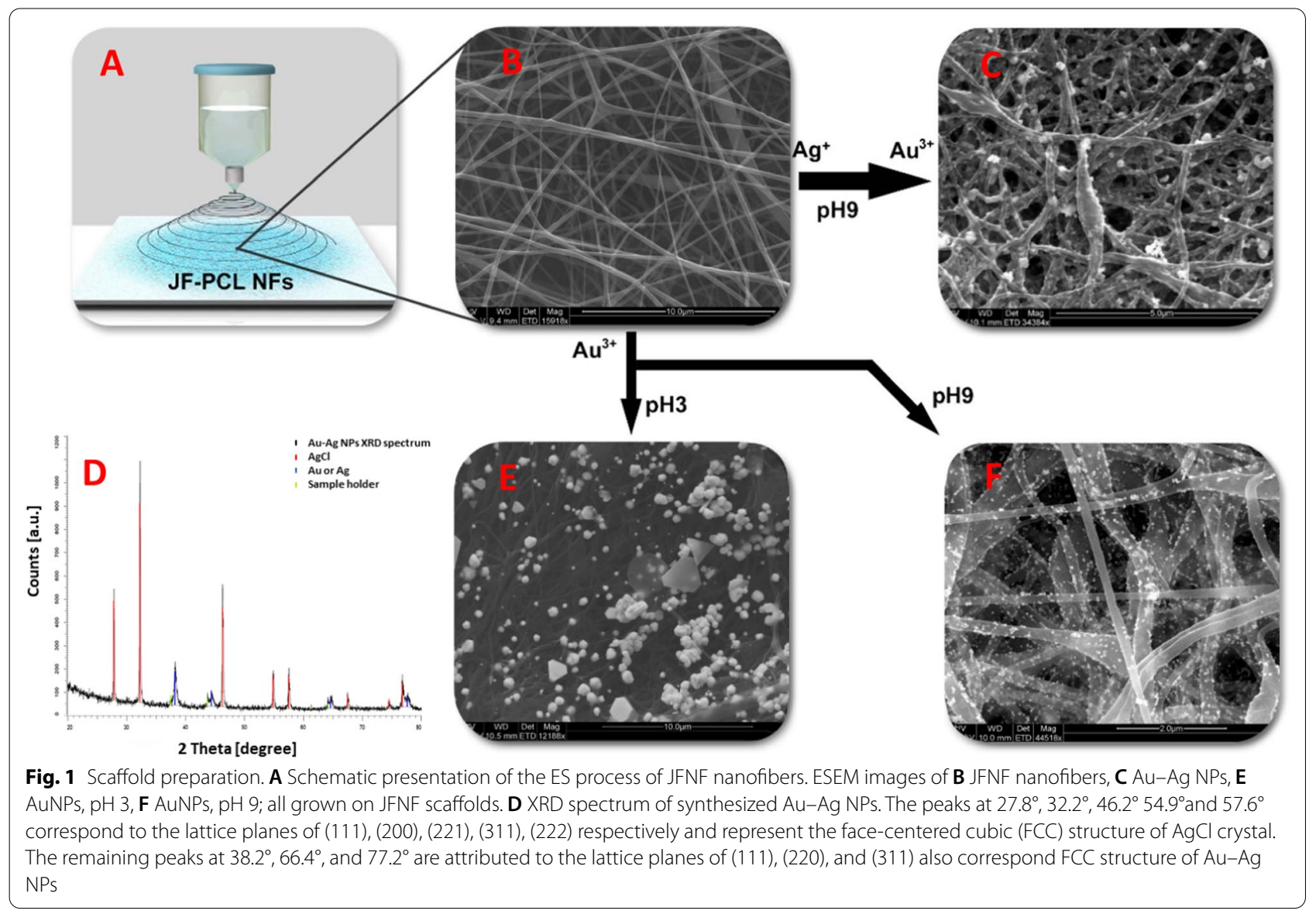


( $\mathrm{Au}-\mathrm{Ag})$ NPs complexes on the JFNF in pivotal acidic $(\mathrm{pH} 3)$ and alkaline $(\mathrm{pH} 9)$ environments. Figure $1 \mathrm{C}-\mathrm{F}$ Shows Environmental Scanning Electron Microscopy (ESEM) images and corresponding X-ray diffraction (XRD) spectra of the scaffold. At $\mathrm{pH} 3$, large spherical particles and hexagonal and triangular crystals were found (Fig. 1D, Additional file 1: Figure S3; Table S1), while small particles were generated at alkaline conditions. The phenomenon is attributed to the disulfide bonds protonation allowing the formation of a large area available for the synthesis at $\mathrm{pH} 3$, resulting in large crystalline structures. In contrast, the disulfide bonds are deprotonated and tightly packed under alkaline conditions, limiting the volume and area of nucleation, resulting in small spherical AuNPs (Fig. 1E, Additional file 1: Figure S4; Table S1).

Next, we synthesized the bimetallic NPs. In this study, $\mathrm{Ag}$ and $\mathrm{Au}$ ions were added simultaneously to the scaffold in alkaline $\mathrm{pH}$. Figure $1 \mathrm{C}$ depicts the ESEM images showing the synthesized particles. With the limitation of the characterization techniques, we hypothesize that the obtained structures are in the form of Au-Ag solid-solution as often obtained in the steady-state phase diagram [34]. XRD analysis (Fig. 1D and Additional file 1: Figure S5) of the bimetallic NPs clearly indicates the formation of $\mathrm{Au}, \mathrm{Ag}$, and $\mathrm{AgCl}$ crystals.

Correlation between the chemical reducing substrate (JFNF) properties and the size and structures of NPs reveals that larger fibers facilitated the growth of larger spherical particles than smaller-diameter ones (Table S1). The effect of fiber diameter on triangular and hexagonal Au particles' growth is inconclusive due to the diverse particle population obtained. No correlation between the content of the solution and particle size was found (Additional file 1: Figure S6). Changing the $\mathrm{pH}$ didn't affect the morphological structure of the JFNF and they retained their original structure.

\section{Photothermal properties of AuNPs and Ag-Au NPs}

Figure 2 and Additional file 1: Figure S7 show the results of time-resolved PT measurements (excitation at $\lambda=808 \mathrm{~nm}$ ) as a function of the synthesis $\mathrm{pH}$, irradiation time, and laser power.

While it is evident that the pristine scaffold did not show PT characteristics, the NPs-doped scaffolds exhibited pronounced PT properties: AuNPs synthesized at $\mathrm{pH} 3$ reached an elevated temperature of $\sim 45{ }^{\circ} \mathrm{C}$, while the ones synthesized at $\mathrm{pH} 9$ reached a higher temperature of $80{ }^{\circ} \mathrm{C}$. Notably, the bimetallic NPs produced at this $\mathrm{pH}$ showed a similar PT profile, indicating that these can function both as antibacterial and PT materials.

The time-dependent characteristics can be understood in light of thermogravimetric analysis (TGA, Additional file 1: Figure S8) of these materials, which shows a distinct melting point of the host scaffold around $60^{\circ} \mathrm{C}$, corresponding to the sharp increase in the PT profiles. This transition was not observed in AuNPs produced at $\mathrm{pH} 3$ since the maximum heating temperature did not reach the melting point. The difference between the PT characteristics found in $\mathrm{pH} 3$ and $\mathrm{pH} 9$ can be attributed to the different size and dispersion of the particles produced in the syntheses (see also Additional file 1: Figures S3, S4; Table S1): It is known that light localization at hot spots between the dense population of particles, increases the amount of non-radiative processes which are transferred to heat [35]. Therefore, heat is generated more efficiently at the small and dense population $(\mathrm{pH} 9)$ than at the large and scattered ones ( $\mathrm{pH} 3)$.

\section{Antibacterial and antibiofilm activity}

The PT experiments allowed us to optimize and tune the conditions needed to be applied in the PT-induced antibacterial and antibiofilm experiments. In this respect, we choose irradiation times of $\sim 60 \mathrm{~s}$ at moderate laser power $\left(1 \mathrm{~W} / \mathrm{Cm}^{2}\right)$, which allows heating the scaffold to desired temperatures without damaging it.

To evaluate the scaffold's antibacterial ("passive") and PT-induced ("active") properties, we performed disk diffusion antibacterial qualitative assays against gram-positive Bacillus subtilis bacteria known for their resistance to the harsh environment [36]. Additional file 1: Figure S9 shows the results of the assay tested with and without laser irradiation. Clear evidence of antibacterial activity is shown in scaffolds with $\mathrm{Au}-\mathrm{Ag}$ NPs. ESEM scan of the inhibition zone highlights the borderline between the treated area, which clearly became bacteria-free, and the untreated one (Fig. 3A).

Next, the antibiofilm properties of scaffolds with $\mathrm{Au}-$ Ag NPs were evaluated. In this case, due to the high resistance properties of the matured biofilms, we also applied PT treatment.

It is evident that upon irradiation (Fig. 3 and Additional file 1: Figure S9), mature biofilms located directly underneath the NP-decorated scaffolds were denatured. The corresponding ESEM images indicated that the produced thermal shock had caused massive damage to the bacteria's membrane, causing membrane collapse (Fig. 3B, C). Due to that short lasing time, it can be concluded that the destruction of the biofilm takes place solely because of the hightemperature increment and not due to the passive antibacterial effect, which occurs at longer time scales. However, we have found that the irradiated bimetallicbased scaffolds kept the treated surface clean of biofilms for at least $24 \mathrm{~h}$ after removal in contrast to the AuNPs-based scaffold in which regrowth of colonies 

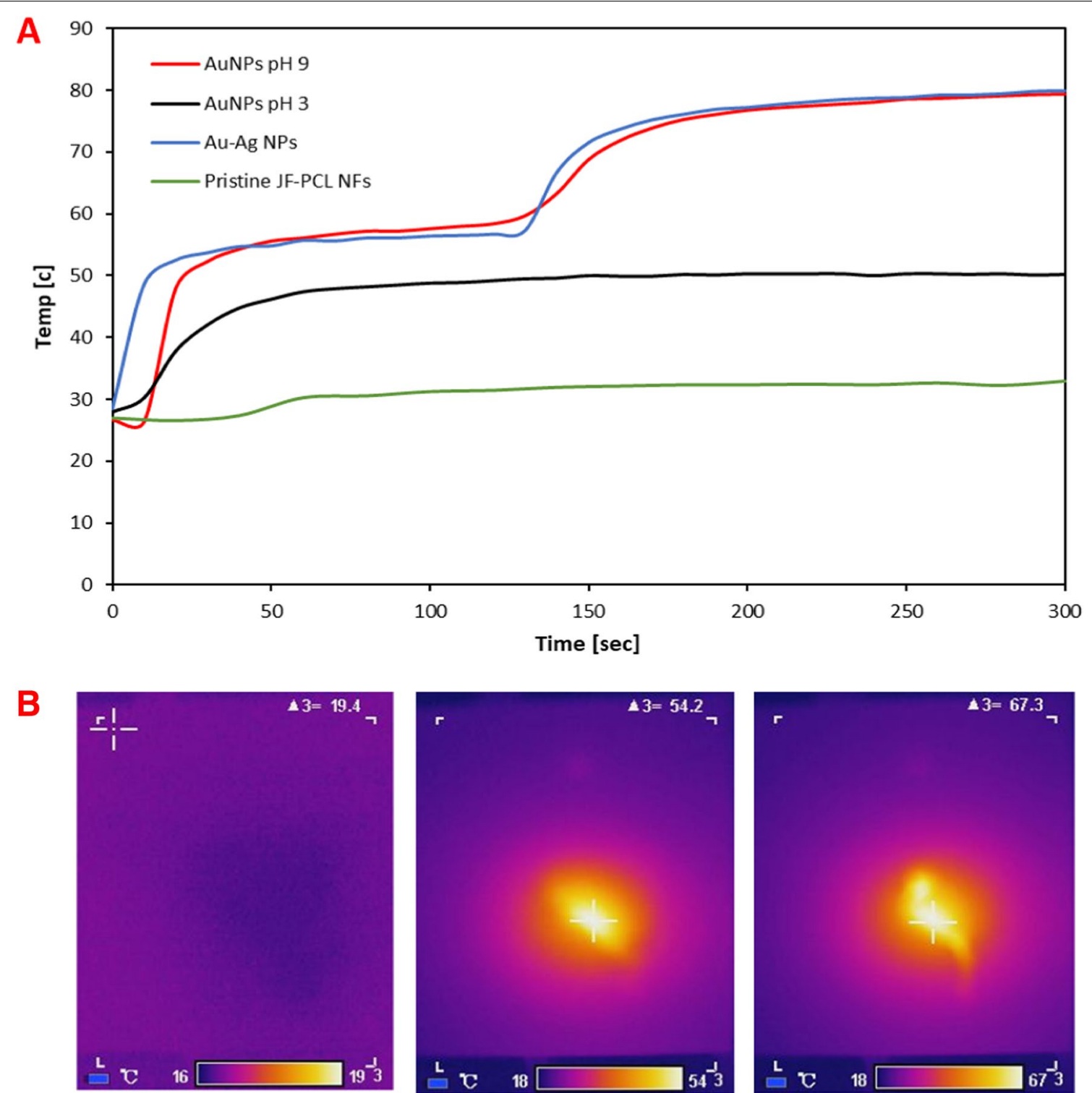

Fig. 2 PT characterization. A Time-dependent measurements of AuNPs and Au-Ag NPs on JFNF scaffold synthesized at different pH. B Thermal images of the scaffold decorated with Au-Ag NPs taken at (left) $t=0$, (middle) $t=60 \mathrm{~s}$, and (right) $t=150 \mathrm{~s}$

was found (Fig. 4 and Additional file 1: Figure S10). We attribute this observation to the diffusion of the antibacterial silver ions from the NPs to the surface, making this surface resistant to bacterial regrowth.

Laser irradiation applied to a reference sample composed of a pristine scaffold did not affect the bacterial colony. Interestingly, this type of scaffold exhibited strong adhesion to the biofilm, causing partial biofilm removal from the growth medium to the scaffold without the need for heating (Additional file 1: Figure S10).

\section{Quantitative antibacterial growth inhibition assay}

To check the validity of our methodology to different types of bacteria, we performed a quantitative antibacterial growth inhibition assay in aqueous media. This was done using three different bacterial strains: E. coli (Gramnegative) (Fig. 5A), S. epidermidis (Gram-positive) (Fig. 5B), and P. aeruginosa (Gram-negative, Fig. 5C), a pathogenic bacterium capable of forming biofilm layers, as a model bacterial strain. 

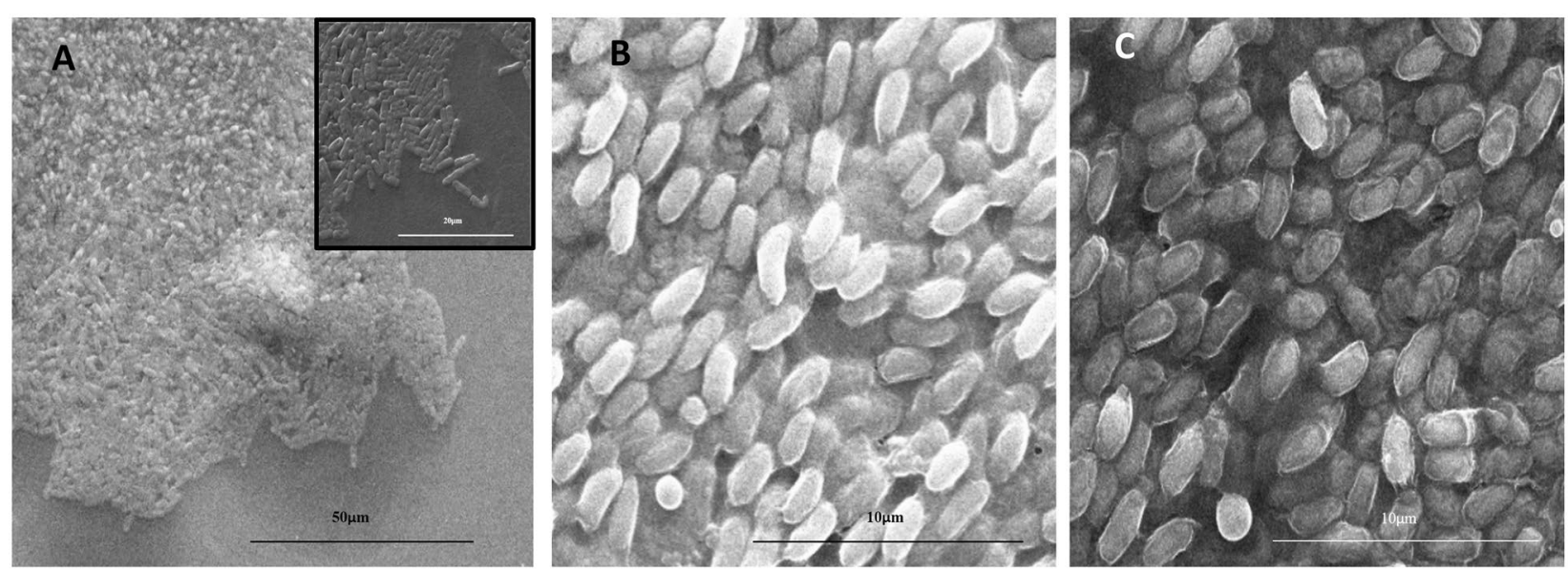

Fig. 3 ESEM images of: $\mathbf{A}$ the area after the disk-diffusion test. The treated regime is clear of bacteria, while the bacteria at the periphery are present; inset: zoom-in of the borderline. B Bacteria cultures in the area that was not irradiated by laser. The bacteria colony remained alive. C The area underneath JFNF scaffold loaded with Au-Ag NPs after 60 s of laser irradiation. The damage to the bacteria's EPS 's is clearly seen

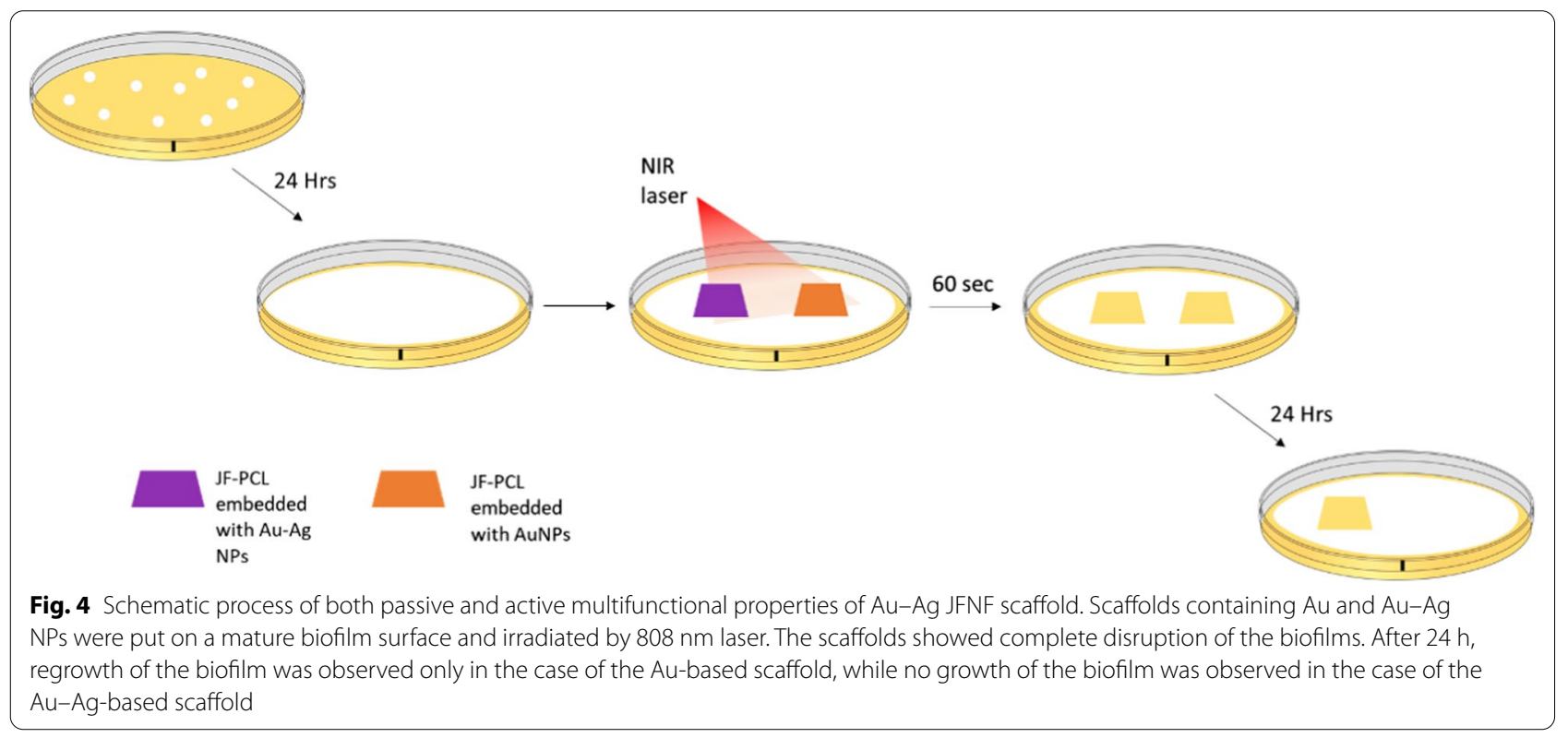

The analyses indicate that the growth of all three tested bacterial strains was utterly inhibited by scaffolds decorated with $\mathrm{Au}-\mathrm{Ag} \mathrm{NP}$ and AuNPs (pH 3), and this, with and without application of laser. These observations suggest that the scaffold's passive antibacterial activity exhibits high antibacterial properties, and laser irradiation is not required to suppress bacterial growth in these cases, as the difference between the two in each scaffold was not significant.

Surprisingly, despite their excellent PT properties, AuNPs ( $\mathrm{pH}$ 9)-based scaffold showed no significant inhibition with or without the laser irradiation except in the case of S. epidermidis (Fig. 5B). This can be attributed to the slow diffusion of metal ions and short irradiation time, which was inefficient in damaging the bacteria in this particular case. In all cases, pristine fibers scaffold without the Np did not show any antibacterial effect with and without laser irradiation.

\section{Quantitative antibiofilm inhibition assay}

Finally, we performed quantitative analysis on mature $P$. aeruginosa BFs (Fig. 5D). It is evident that scaffolds that contain NPs successfully devastated the BF. The 

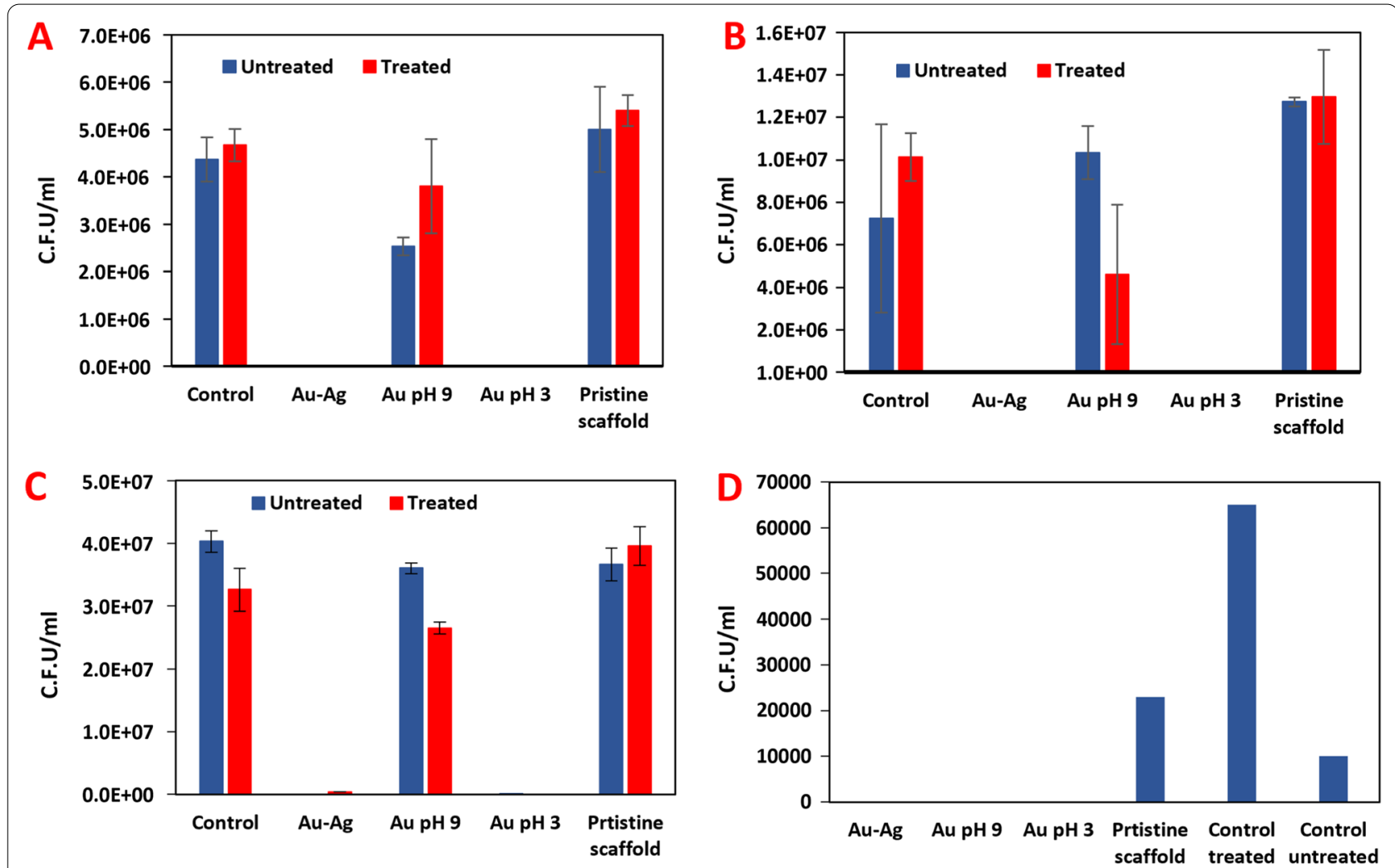

Fig. 5 A-C Colony-Forming Unit (CFU) counts of bacteria approximately $24 \mathrm{~h}$ after addition of the scaffolds composed of bacterial growth substrate ("control "), bimetallic NPs ("Au-Ag "), AuNP synthesized at pH9, at pH3, and of a scaffold without NPs ("pristine scaffold"). The graphs present results acquired with and without laser irradiation ("treated" and untreated", repectively), performed on E. coli (A), S. epidermidis (B) and P. aeruginosa $(\mathbf{C})$ assays. D CFU analysis of $P$. aeruginosa biofilm. All samples that contained NPs showed destruction of the BFs underneath them and bacterial death compared to the controls

heat generated by the irradiated Au-Ag NP and AuNP ( $\mathrm{pH} 3$ \& $\mathrm{pH}$ 9) was sufficient to completely denaturate the biofilm beneath the scaffolds even in a short irradiation time of $30 \mathrm{~s}$ by this "sanitizing" the solid growth medium. In this case, the passive antibacterial function of the scaffolds is not necessary for bacterial removal but is nevertheless very useful for the prevention of new contaminations as demonstrated in the qualitative assay which was performed on Bacillus subtilis biofilm (Fig. 3, Additional file 1: Figure S11).

Reference experiments performed on pristine JFNF scaffold (Fig. 5A-C "pristine scaffold") showed no significant antibacterial activity, with or without laser treatment. In addition, direct irradiation by laser on the bacteria or biofilm did not show any inhibition growth or biofilm removal.

\section{Conclusions}

In summary, the synthesis and the characteristics of a novel anti-biofilm scaffold is demonstrated. The scaffold is comprised of electrospun Jellyfish-based nanofibers decorated with bimetallic nanoparticles. The dual functionality of the scaffold was evaluated via its photothermal and antibacterial properties. We leverage these properties and demonstrate how this scaffold can successfully disrupt, remove and eliminate the regrowth of mature biofilms colonies. We believe that this novel scaffold can be used for advanced treatments in many medical applications such as wound dressing, infections, and sensitive infected areas.

\section{Experimental section and methods}

Materials

Hydrogen tetrachloroaurate hydrate; 99.9\%, $\mathrm{Au}$

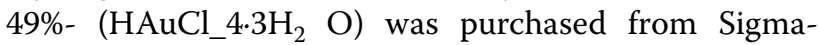
Aldrich. Silver nitrate 99.999\% (AgNO3); Glycine, and sodium hydroxide $(\mathrm{NaOH})$ were all purchased from Sigma-Aldrich.

\section{JFNF Production}

JFNF were prepared in the same manner as we previously described in ref [22]. Shortly, different w\%/w\% solutions of JF-Polycaprolactone (PCL)/AcOH solutions were electrospun under $12-17 \mathrm{kV}$ voltage with a controlled flow 
rate of $2-3 \mu \mathrm{l} / \mathrm{min}$, a distance of $25 \mathrm{~cm}$ in $\mathrm{RT}$, and $70 \%$ humidity.

\section{Synthesis of AuNPs}

A $1 \mathrm{~cm} \times 1 \mathrm{~cm}$ piece of JFNF was added to $3 \mathrm{ml} \mathrm{HAuCl}$ - 4.3H_2 O $2.5 \mathrm{mM}$ in a $20 \mathrm{ml}$ vial. The vial was covered with an aluminum sheet and was stirred for $20 \mathrm{~min}$. Next, $2 \mathrm{ml}$ of glycine buffer of $\mathrm{pH} 3$ or 9 was added, and nitrogen gas was injected into the vial. The synthesis was kept stirred for six days. After the reaction completion, the NFs scaffold was washed with water and dried in the fume hood.

\section{Synthesis of Au-Ag NPs complex}

A $1 \mathrm{~cm} \times 1 \mathrm{~cm}$ piece of $\mathrm{NF}$ was added to $3 \mathrm{ml}$ HAuCl_4.3H_2 O $2.5 \mathrm{mM}$ in a $20 \mathrm{ml}$ vial and stirred for $20 \mathrm{~min}$. After the initial stirring, $2 \mathrm{ml}$ of glycine buffer $\mathrm{pH} 9$ was added along with $0.25 \mathrm{ml}$ of $0.1 \mathrm{M} \mathrm{AgNO}_{3}$ and nitrogen gas injection. The vial was covered with aluminum and kept stirred for six days. After the reaction completion, the NFs scaffold was washed with water and dried in a fume hood.

\section{Characterizations}

ESEM imaging was carried out with the Quanta 200 FEG Environmental scanning electron microscope with an operational voltage of $20 \mathrm{kV}$. Sputtering of $10 \mathrm{~nm}$ gold was required prior to ESEM imaging for contrast enhancement. The Spattering was performed with the SPI sputter at $1.2 \mathrm{kV}$ for $120 \mathrm{~s}$.

$\mathrm{X}$-ray diffraction was performed by initial sample preparation, which included centrifugation of prepared $\mathrm{Au}$ and Ag NPs at $1000 \mathrm{rpm}$ for $5 \mathrm{~min}$, and further drying of the particles under vacuum.

Thermal analysis and confocal microscopy were employed to determine the thermal properties and the chemical composition of the NFs scaffolds. These techniques are elaborately explained in the SI section.

\section{Photothermal laser test}

For the PT measurement, a home-built system consists of NIR laser (Laser Power Supply, model no. PSU-H-LED, 808 nm, By Changchun New Industries Optoelectronics Tech. co., LTD.) coupled with a thermal camera and confined in an optically sealed box. Different samples (slightly wet with $\mathrm{dH}_{2} \mathrm{O}$ ) of JFNF scaffolds with $\mathrm{Au}$ - and AgNPs were put on glass slides and irradiated with an IR beam. The temperature of the scaffold was measured by a thermal camera (IR-CAM-160 by MRC). The samples were irradiated for 5 min with $1 \mathrm{~W}$.

\section{Disk diffusion antibacterial essay}

Nutrient agar plates from a solution of Luria agar base were prepared, to create a substrate for bacteria growth. A $40 \mu \mathrm{L}$ sample of bacteria was plated on each substrates and then heated on $37^{\circ} \mathrm{C}$ for $10 \mathrm{~min}$ (upside down). The substrates were supplemented with NFs scaffolds covered with silver/gold NPs. The substrates were incubated for $24 \mathrm{~h}$ in the oven at $37^{\circ} \mathrm{C}$, as well as NPs-free plate and the commercial pad was used as a control. The area of clear solution underneath the NFs scaffolds was examined on each of the plates (cloudy areas indicate the growth of bacteria colonies).

\section{Laser test with Bacillus subtilis p479 biofilm}

NFs scaffolds with Gold and Silver NPs were put on cultures of bacteria (the same procedure as described under "Antibacterial test"), and were radiated by IR beam for $60 \mathrm{~s}$. The scaffolds were removed, and the cultures were put under the gauze pad soaked with glutaraldehyde (25\%) for an hour to absorb the vapors (for the preservation of the bacteria). Then the petri dishes were put in a desiccator for dehydration for few days.

\section{Bacterial growth inhibition assay}

Escherichia coli (K-12 strain, WT) bacteria were grown overnight in M9 minimal media and diluted 500-fold in M9 media. Staphylococcus epidermidis (ATCC 12228) bacteria were grown overnight in LB media and diluted 1,000-fold in LB media. Pseudomonas aeruginosa (ATCC 27853) bacteria were grown overnight in LB media and diluted 1,000-fold in LB media. Samples were placed in 2 Corning (3879) 96-well plates (Sigma-Aldrich, Israel), three repetitions per plate for each bacteria. $100 \mu \mathrm{l}$ volumes of growth medium containing bacteria $(5 \times 106$ $\mathrm{CFU} / \mathrm{ml}$ ) were added to each well. Post treatment, the plates were covered with Breathe-Easy sealing membrane (Sigma-Aldrich, Israel) and incubated at $37^{\circ} \mathrm{C}$ overnight. Growth inhibition was evaluated by CFU-count. Bacteria marked as control were grown solely in bacterial media, without any alterations.

\section{Supplementary Information}

The online version contains supplementary material available at https://doi. org/10.1186/s12951-021-01183-x.

Additional file 1: Figure S1. (a) A confocal microscope image of 25/75 JF/PCL NFs (applied voltage 13kV) labeled with DTAF ( 20 magnitude). (b) A confocal microscope image of 75/25 JF/PCL NFs (applied voltage 13kV) labeled with DTAF (x20 magnitude). (c) A column graph which displays the difference between the NFs intensities ( $x 10$ magnitude) as a function of the applied voltage and JF/PCL ratio. Figure S2. Mechanical properties of JF/PCL scaffolds (A) Young's modulus as a function of JF/PCL ratio. (B) Column graph which displays the difference between the NFs thickness as a function of the applied voltage and JF/PCL ratio. (C) Column graph which displays the difference between the NFs porosity Stress-strain curve 
as a function of JF/PCL ratio for (D) $13 \mathrm{kV}$ and (E) $17 \mathrm{kV}$ as a function of the applied voltage and JF/PCL ratio. Figure S3. AuNPs synthesized with $\mathrm{pH}$ 3 on different JF/PCL NFs scaffolds. (a) 25/75 (b) 33/66 (c) 50/50 (d) 66/33 (e) $75 / 25$. Figure S4. AuNPs synthesized with $\mathrm{pH} 9$ on different JF/PCL NFs scaffolds. (a) 25/75 (b) 33/66 (c) 50/50 (d) 66/33 (e) 75/25. Figure S5 XRD of AuNPs in pH 3 and pH 9. Inset is XRD of pristine JF/PCL scaffold. Figure S6. Particle size dependence on JF/PCL component ratio. Figure S7. Au-Ag NPs on NFs scaffold under different power output of 808nm laser. Figure S8. (a) DTA curves of 66/33 and 33/66 JF/PCL scaffolds. (b) TGA curves of 66/33 and 33/66 JF/PCL scaffolds. Figure S9. Disk diffusion test of Au NPs pH 9, AgNPs, Au-Ag NPs on NFS scaffolds, after 24 hours on a bacteria culture. (A) Bacteria substrates before scaffolds were removed. (B) bacteria substrates after scaffolds were removed. Au-Ag NPS (NFS scaffolds) that were put on bacteria culture (C) before laser NIR laser irradiation. (D) after 60 seconds of laser irradiation. (G) in area underneath NFS scaffold (50/50 13kv) with Au and Ag after 60 seconds of irradiation. Figure S10. (a) Area underneath pristine NFs scaffold (without NPs) after irradiation with laser for $60 \mathrm{sec}$. (b) ESEM image of the scaffold after irradiation. Figure S11. (a) Swab sample that were taken underneath scaffolds after laser irradiation. (b) Swab sample that were taken underneath the same scaffolds after incubation for 24 hours. Table S1. T-Test for AuNPs size grown in different conditions- $\mathrm{pH}$ and JF/PCL scaffold

\section{Acknowledgements}

Not applicable.

\section{Authors' contributions}

RN, SG, DB, MB and TG performed the experiments. RN, SG, EG and SR wrote the paper. All authors read and approved the final manuscript.

\section{Funding}

Not applicable.

\section{Availability of data and materials}

Not applicable.

\section{Declarations}

\section{Ethics approval and consent to participate}

Not applicable.

\section{Consent for publication}

Not applicable.

\section{Competing interests}

The authors declare that they have no competing interests.

\section{Author details}

'Department of Materials Science and Engineering, Faculty of Engineering, Tel Aviv University, 69978 Tel-Aviv, Israel. ${ }^{2}$ University Center for Nano Science and Nanotechnology, Tel-Aviv, Israel. ${ }^{3}$ The Shmunis School of Biomedicine and Cancer Research, Faculty of Life Sciences, The George S. Wise, Tel-Aviv, Israel.

Received: 6 October 2021 Accepted: 4 December 2021 Published online: 28 December 2021

\section{References}

1. Hall-Stoodley L, Stoodley P. Evolving concepts in biofilm infections. Cell Microbiol. 2009;11:1034-43. https://doi.org/10.1111/j.1462-5822.2009. 01323.x.

2. Das T, Sehar S, Manefield M. The roles of extracellular DNA in the structural integrity of extracellular polymeric substance and bacterial biofilm development. Environ Microbiol Rep . John Wiley \& Sons, Ltd; 2013;5:77886. Available from: https://doi.org/10.1111/1758-2229.12085
3. Donlan R. Biofilms: Microbial Life on Surfaces. Emerg Infect Dis J . 2002;8:881. https://wwwnc.cdc.gov/eid/article/8/9/02-0063_article

4. Fish KE, Osborn AM, Boxall J. Characterising and understanding the impact of microbial biofilms and the extracellular polymeric substance (EPS) matrix in drinking water distribution systems. Environ Sci water Res Technol. 2016;2:614-30.

5. Reid G. Biofilms in infectious disease and on medical devices. Int J Antimicrob Agents . 1999;11:223-6. http://www.sciencedirect.com/science/artic le/pii/S0924857999000205

6. Lewis K. Riddle of biofilm resistance. Antimicrob agents chemother American Society for Microbiology Journals; 2001;45:999-1007. https:// aac.asm.org/content/45/4/999

7. Percival SL, Suleman L, Vuotto C, Donelli G. Healthcare-associated infections, medical devices and biofilms: risk, tolerance and control. J Med Microbiol. 2015;64:323-34. https://doi.org/10.1099/jmm.0.000032.

8. Bridier A, Briandet R, Thomas V, Dubois-Brissonnet F. Resistance of bacterial biofilms to disinfectants: a review. Biofouling. 2011;27:1017-32. https://doi.org/10.1080/08927014.2011.626899.

9. Meyer B. Approaches to prevention, removal and killing of biofilms. Int Biodeterior Biodegrad. 2003;51:249-53. http://www.sciencedirect.com/ science/article/pii/S0964830503000477

10. Simões M, Simões LC, Machado I, Pereira MO, Vieira MJ. Control of flowgenerated biofilms with surfactants: evidence of resistance and recovery. Food Bioprod Process. 2006;84:338-45. http://www.sciencedirect.com/ science/article/pii/S0960308506705582

11. Yin W, Wang Y, Liu L, He J. Biofilms: The microbial "Protective Clothing" in extreme environments. Int J Mol Sci. 2019;20:3423. https://pubmed.ncbi. nlm.nih.gov/31336824

12. Ratka C, Weigl P, Henrich D, Koch F, Schlee M, Zipprich H. The effect of in vitro electrolytic cleaning on biofilm-contaminated implant surfaces. J Clin Med. 2019:8:1397. https://pubmed.ncbi.nlm.nih.gov/31500093

13. Mandell JB, Deslouches B, Montelaro RC, Shanks RMQ, Doi Y, Urish KL. Elimination of antibiotic resistant surgical implant biofilms using an engineered cationic amphipathic peptide WLBU2. Sci Rep. 2017;7:18098. https://doi.org/10.1038/s41598-017-17780-6.

14. Baker C, Pradhan A, Pakstis L, Pochan DJ, Shah SI. Synthesis and antibacterial properties of silver nanoparticles. J Nanosci Nanotechnol. 2005:5:244-9

15. Pal S, Tak YK, Song JM. Does the Antibacterial activity of silver nanoparticles depend on the shape of the nanoparticle? A study of the gram-negative bacterium Escherichia coli. Appl Environ Microbiol. 2007;73:1712-20. https://aem.asm.org/content/73/6/1712

16. Guo J, Qin S, Wei Y, Liu S, Peng H, Li Q, et al. Silver nanoparticles exert concentration-dependent influences on biofilm development and architecture. Cell Prolif. 2019;52:e12616-e12616. https://pubmed.ncbi.nlm.nih. gov/31050052

17. Xie X, Mao C, Liu X, Tan L, Cui Z, Yang X, et al. Tuning the bandgap of photo-sensitive polydopamine/Ag3PO4/graphene oxide coating for rapid, noninvasive disinfection of implants. ACS Cent Sci. 2018;4:724-38. https://doi.org/10.1021/acscentsci.8b00177.

18. Jo W, Kim MJ. Influence of the photothermal effect of a gold nanorod cluster on biofilm disinfection. Nanotechnology. 2013;24:195104. https:// doi.org/10.1088/0957-4484/24/19/195104.

19. Yatvin MB. The influence of membrane lipid composition and procaine on hyperthermic death of cells. Int J Radiat Biol Relat Stud Phys Chem Med. 1977;32:513-21. https://doi.org/10.1080/09553007714551301.

20. Maksimova IL, Akchurin GG, Khlebtsov BN, Terentyuk GS, Akchurin GG, Ermolaev IA, et al. Near-infrared laser photothermal therapy of cancer by using gold nanoparticles: computer simulations and experiment. Med Laser Appl. 2007;22:199-206.

21. Huang X, Jain PK, El-Sayed IH, El-Sayed MA. Plasmonic photothermal therapy (PPTT) using gold nanoparticles. Lasers Med Sci. 2007;23:217. https://doi.org/10.1007/s10103-007-0470-X.

22. Bermúdez-Jiménez C, Niño-Martínez N, Patiño-Marín N, Martínez-Gutiérrez F, Ruiz F, Bach $\mathrm{H}$, et al. Effective control of biofilms by photothermal therapy using a gold nanorod hydrogel. J Biomed Mater Res Part B Appl Biomater. 2020;108:333-42. https://doi.org/10.1002/jbm.b.34392.

23. Ghosh S, Jagtap S, More P, Shete UJ, Maheshwari NO, Rao SJ, et al. Dioscorea bulbifera mediated synthesis of novel Au(core)Ag(shell) nanoparticles with potent antibiofilm and antileishmanial activity. Obare 
S, editor. J Nanomater 2015;2015:562938. Doi: https://doi.org/10.1155/ 2015/562938

24. Diem PNH, Phuong TNM, Hien NQ, Quang DT, Hoa TT, Cuong ND. Silver, gold, and silver-gold bimetallic nanoparticle-decorated dextran: facile synthesis and versatile tunability on the antimicrobial activity. Wang $\mathrm{R}$, editor. J Nanomater. 2020;2020:7195048. Doi: https://doi.org/10.1155/ 2020/7195048

25. Salunke GR, Ghosh S, Santosh Kumar RJ, Khade S, Vashisth P, Kale T, et al. Rapid efficient synthesis and characterization of silver, gold, and bimetallic nanoparticles from the medicinal plant Plumbago zeylanica and their application in biofilm control. Int J Nanomedicine. 2014;9:2635-53. https://pubmed.ncbi.nlm.nih.gov/24920901

26. Elegbede JA, Lateef A. Green synthesis of silver (Ag), gold (Au), and silvergold (Ag-Au) alloy nanoparticles: a review on recent advances, trends, and biomedical applications. Nanotechnol Nanomater Appl Food Heal Biomed Sci. 2019. https://doi.org/10.1201/9780429425660-1.

27. Nudelman R, Alhmoud H, Delalat B, Fleicher S, Fine E, Guliakhmedova T, et al. Jellyfish-based smart wound dressing devices containing in situ synthesized antibacterial nanoparticles. Adv Funct Mater. 2019;29:1902783. https://doi.org/10.1002/adfm.201902783.

28. Hendler N, Fadeev L, Mentovich ED, Belgorodsky B, Gozin M, Richter S. Bio-inspired synthesis of chiral silver nanoparticles in mucin glycoprotein - the natural choice. Chem Commun. 2011;47:7419-21. https://doi. org/10.1039/C1CC11228G.

29. Gavriely S, Hadibrata W, Nudelman R, Aydin K, Richter S. One-pot bio-assisted synthesis of stable $\mathrm{Ag}-\mathrm{AgCl}$ system using jellyfish-based scaffold for plasmonic photocatalysis applications. Adv Sustain Syst. 2021;5:2100099. https://doi.org/10.1002/adsu.202100099.

30. Steinberger LR, Gulakhmedova T, Barkay Z, Gozin M, Richter S. Jellyfishbased plastic. Adv Sustain Syst. 2019;3:1900016. https://doi.org/10.1002/ adsu.201900016.

31. Masuda A, Baba T, Dohmae N, Yamamura M, Wada H, Ushida K. Mucin (Qniumucin), a glycoprotein from jellyfish, and determination of its main chain structure. J Nat Prod. 2007;70:1089-92.

32. Vanýsek P. Electrochemical series. In: Haynes WM, editor. CRC handbook of chemistry and physics. 92nd ed. CRC Press; 2011.

33. Nudelman R, Gloukhikh E, Rekun A, Richter S. Investigation of the pHdependence of dye-doped protein-protein interactions. Protein Sci. 2016;25:1918-23. https://doi.org/10.1002/pro.3021.

34. Elliott RP, Shunk FA. The Ag-Au (Silver-Gold) system. Bull Alloy Phase Diagr. 1980;1:45-7. https://doi.org/10.1007/BF02881183.

35. Khorashad LK, Besteiro LV, Wang Z, Govorov A. Localization of excess temperature using plasmonic hot spots in metal nanostructures: combining nano-optical antennas with the fano effect. J Phys Chem C. 2016;120(24):13215-26. https://doi.org/10.1021/acs.jpcc.6b03644.

36. Nicholson WL, Munakata N, Horneck G, Melosh HJ, Setlow P. Resistance of bacillus endospores to extreme terrestrial and extraterrestrial environments. Microbiol Mol Biol Rev. 2000;64:548-72. https://doi.org/10.1128/ MMBR.64.3.548-572.2000.

\section{Publisher's Note}

Springer Nature remains neutral with regard to jurisdictional claims in published maps and institutional affiliations.

Ready to submit your research? Choose BMC and benefit from:

- fast, convenient online submission

- thorough peer review by experienced researchers in your field

- rapid publication on acceptance

- support for research data, including large and complex data types

- gold Open Access which fosters wider collaboration and increased citations

- maximum visibility for your research: over 100M website views per year

At BMC, research is always in progress.

Learn more biomedcentral.com/submissions 